\title{
Phylogenetic Position of Taylorella equigenitalis Determined by Analysis of Amplified 16S Ribosomal DNA Sequences
}

\author{
NANCY M. C. BLEUMINK-PLUYM, LINDA VAN DIJK, ARNOUD H. M. VAN VLIET, \\ JOHANNA W. B. VAN DER GIESSEN, AND BERNARD A. M. VAN DER ZEIJST* \\ Department of Bacteriology, Institute of Infectious Diseases and Immunology, School of \\ Veterinary Medicine, Universiteit Utrecht, P.O. Box 80.165, \\ 3508 TD Utrecht, The Netherlands
}

\begin{abstract}
The 16S ribosomal DNA sequence of Taylorella equigenitalis (formerly Haemophilus equigenitalis), the causative organism of contagious equine metritis, was determined. $A$ phylogenetic analysis of this sequence revealed a phylogenetic position of $T$. equigenitalis in the $\beta$ subclass of the class Proteobacteria apart from the position of Haemophilus influenzae, which belongs to the $\gamma$ subclass of Proteobacteria. A close phylogenetic relationship among $T$. equigenitalis, Alcaligenes xylosoxidans, and Bordetella bronchiseptica was detected; Spirillum volutans and Chromobacterium fluviatile (Iodobacter fluviatile) were in the same group but slightly removed. This relationship is surprising in view of the considerable differences in the $G+C$ contents of the genomes of these bacteria.
\end{abstract}

Contagious equine metritis is a sexually transmitted bacterial disease of horses that is caused by Taylorella equigenitalis. The disease was reported for the first time by Crowhurst in 1977 (2), and the causative agent was described by Taylor et al. in 1978 (18). Since then, T. equigenitalis has been detected in many countries and in different breeds of horses (19). The initial name of this microaerophilic, gramnegative coccobacillus that causes contagious equine metritis was Haemophilus equigenitalis (18). It was classified in the family Pasteurellaceae as a species incertae sedis belonging to the genus Haemophilus.

The taxonomic position of $T$. equigenitalis was reinvestigated in 1983, and it was compared with phenotypically similar organisms, such as Haemophilus, Moraxella, and Legionella species, by Sugimoto et al. On the basis of DNA base composition and DNA-DNA hybridization data, these authors proposed that Haemophilus equigenitalis should be transferred to a new genus, Taylorella, as $T$. equigenitalis (17).

To further clarify the phylogenetic position of $T$. equigenitalis, we determined the sequence of its $16 \mathrm{~S}$ ribosomal DNA (rDNA).

We cultured type strain NCTC 11184 and strains N480/82 and N610/88 as described previously (1). These $T$. equigenitalis strains have been characterized by field inversion gel electrophoresis; two belong to field inversion gel electrophoresis group A, while strain N610/88 is a member of group C (1).

Genomic DNA was prepared as described by Garcia et al. (5). The 16S rDNA was amplified in a total volume of $100 \mu \mathrm{l}$ by using modified terminal primers fD1 ( $5^{\prime}$-gggctgcAGAGTT TGATCCTGGCTCAG-3') and rD1 (5'-cggatccAAGGAGG GTGATCCAGCCNCA-3') (20) and Taq DNA polymerase (Promega, Madison, Wis.). Primer fD1 contained a 5' Pst I restriction site (lowercase nucleotides). Amplified 16S rDNA that was about $1,500 \mathrm{bp}$ long was isolated from an agarose gel by using a Geneclean kit (Biol01, La Jolla, Calif.) and was made blunt by incubation with the Klenow fragment of DNA polymerase I and $1.67 \mathrm{mM}$ each of the four deoxynucleoside triphosphates for $30 \mathrm{~min}$ at $37^{\circ} \mathrm{C}(21)$. The frag-

\footnotetext{
* Corresponding author.
}

ments were then cut with PstI. The DNA was phenol extracted, ethanol precipitated, and ligated between the EcoRV and PstI sites of pBluescript II KS (Stratagene, La Jolla, Calif.) by using T4 DNA ligase. Plasmid DNAs of clones were purified with a Qiagen plasmid kit (Qiagen, Inc., Chatsworth, Calif.) in accordance with the manufacturer's instructions.

The nucleotide sequences of both strands of the cloned 16S rDNA were determined by using the dideoxy chain termination method (14) and an Autoread laser fluorescent DNA sequencer (Pharmacia). The sequencing reactions were carried out by using an Autoread sequencing kit (Pharmacia) in accordance with the manufacturer's manual. The primers used for sequencing $16 \mathrm{~S}$ rDNA, forward and reverse, were fluorescein isothiocyanate labeled and have been described previously (20).

The sequences of the $T$. equigenitalis $16 \mathrm{~S}$ rDNAs of type strain NCTC 11184 and strains N480/82 and N610/88 were determined. They were identical. The sequence is available from the EMBL, GenBank, and DDBJ nucleotide sequence data bases.

The newly obtained sequence was compared with entries present in the EMBL and GenBank data bases. Close relationships with 16S rDNA sequences of Bordetella bronchiseptica S-1, Alcaligenes xylosoxidans ATCC $15173^{\mathrm{T}}$ (T = type strain), Chromobacterium fluviatile (Iodobacter fluviatile $[8,9])$ ATCC 33051, Legionella pneumophila ATCC $33152^{\mathrm{T}}$, Pseudomonas aeruginosa ATCC 25330 , Escherichia coli, and Spirillum volutans ATCC $19554^{\mathrm{T}}$ were detected. Two hypervariable regions which distinguish the three closest relatives most effectively are shown in Fig. 1. These regions are located at the $5^{\prime}$ end of the $16 \mathrm{~S}$ rDNA at positions 65 to 97 and 412 to 478 ( $E$. coli numbering).

The 16S rDNA sequence of $T$. equigenitalis was aligned with the sequences of the 16S rDNAs of these bacteria. Aligned 16S rRNA sequences were obtained from the Ribosomal Database Project (10). All bacterial sequences were truncated from position 27 (E. coli numbering). Positions at which all of the $16 \mathrm{~S}$ rRNA sequences had a gap were eliminated. This alignment was used for a sequence signature analysis (22) and a phylogenetic analysis.

With additional sequence masking we eliminated positions at which the sequences had gaps. In this way, only those 
T. equigenitalis

A. xylosoxidans

B. bronchiseptica
65

ACGGCAGCA TAAGGAGAGC TTGCTTTTCT TGA

......... C--..GA. ..CG-.C..- -.G

G..................... CG-GCCT- -.G
T. equigenitalis

A. xylosoxidans

B. bronchiseptica
GaGGCTT GGGTTGTAA AGCACTTTTG TCAGGGAAGA AAAGGTTTGT GTTAATACCA TGGACTGCTG ACGGTACCTGA

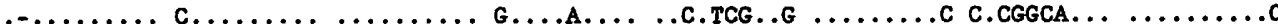

FIG. 1. Two most variable regions of the $16 \mathrm{~S}$ rDNA genes of $T$. equigenitalis, $A$. xylosoxidans, and $B$. bronchiseptica. The first region is located from position 65 to position 97; the second region is located from position 412 to position 478 ( $E$. coli numbering). The dots in the alignments indicate identical sequences; the dashes indicate deletions. Asterisks indicate signature sequences.

positions that were present in all of the sequences were used for the alignment. This sequence masking affected only the lengths of the branches, not the branching order (data not shown).

For the phylogenetic analysis we performed a distance matrix and parsimony analysis, as described in the Felsenstein-Phylip package, version 3.3 (3). The distance matrix FITCH (4) and NJTree (13) algorithms were used for treeing algorithms that assume no evolutionary clock. The KITCH program (4) uses a treeing algorithm that assumes an evolutionary clock.

The evolutionary distance tree generated by the distance matrix analysis and the FITCH program is shown in Fig. 2. $T$. equigenitalis forms a cluster with $A$. xylosoxidans, $B$. bronchiceptica, $S$. volutans, and $C$. fluviatile. The evolutionary distance trees generated by the other programs and by the parsimony analysis program DNAPars were not significantly different from the tree shown in Fig. 2 (data not shown). The levels of sequence identity among the members of this phylogenetic cluster varied between 87.6 and $97.6 \%$ (Table 1).

The cluster belongs to the $\beta$ subclass of the class Proteobacteria (16). The position of $T$. equigenitalis in the $\beta$ subclass is supported by the results of an analysis of the helices between positions 180 and 220 . The first helix, between position 184 and 193, contains $3 \mathrm{bp}$. The second helix, between positions 198 and 219 , contains $9 \mathrm{bp}$, a feature typical of the $\beta$ and $\gamma$ subclasses of Proteobacteria (22). Finally, a sequence signature analysis showed that the $16 \mathrm{~S}$ rRNA of $T$. equigenitalis contains the signature sequences of the $\beta$ subdivision of the purple bacteria in 63 of 66 positions.

The phylogenetic position of $T$. equigenitalis apart from

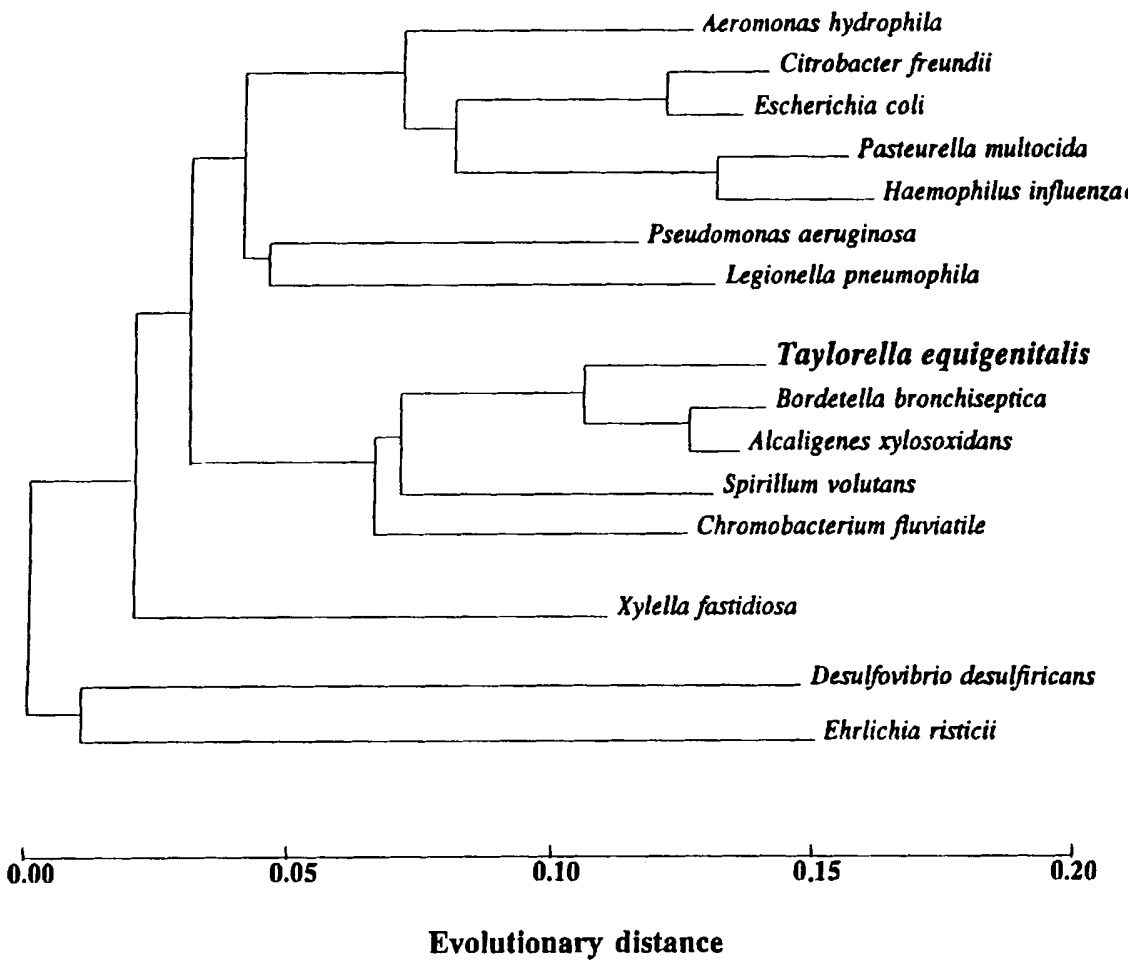

FIG. 2. Evolutionary distance tree generated by distance matrix analysis without sequence masking by using the FITCH program. The evolutionary distances (represented by the lengths of the horizontal lines) are shown in Table 1. 


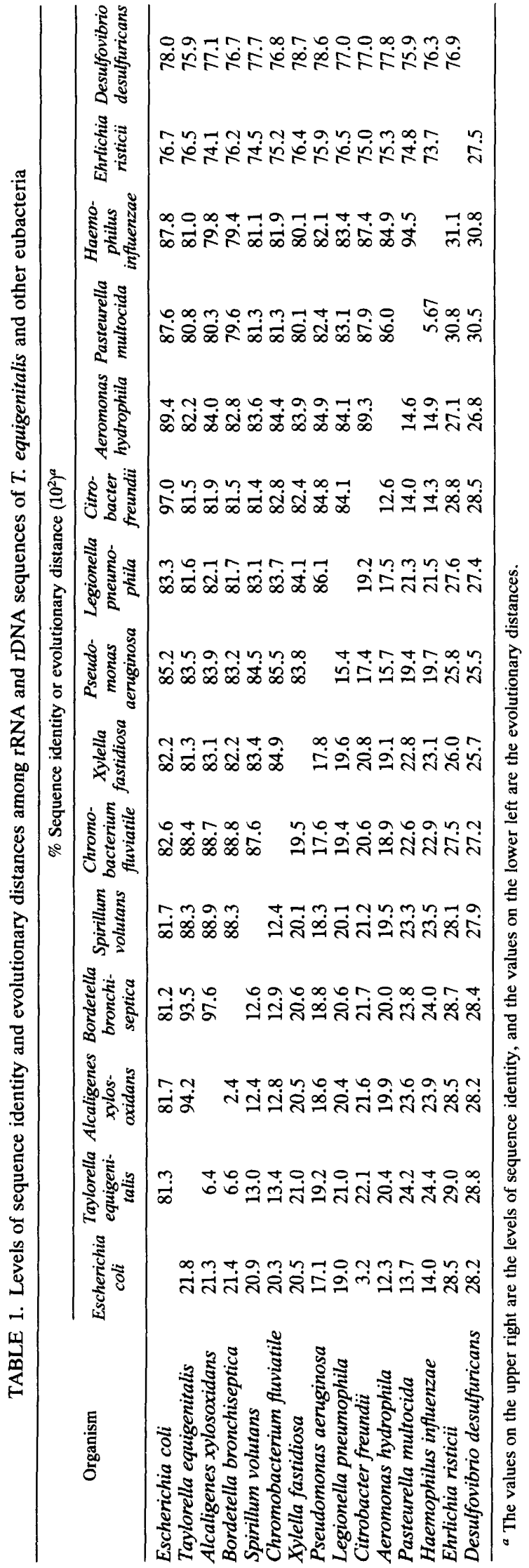

the position of $H$. influenzae, which belongs to the $\gamma$ subclass of Proteobacteria, supports the exclusion of $T$. equigenitalis from the genus Haemophilus and the creation of the genus Taylorella.

The relationship of $T$. equigenitalis to $B$. bronchiseptica, and $A$. xylosoxidans subsp. denitrificans, and other species belonging to rRNA superfamily III was determined by Rossau et al. (12). Despite the low $\mathrm{G}+\mathrm{C}$ content of its genome, these authors included $T$. equigenitalis in rRNA superfamily III on the basis of DNA-rRNA hybridization data.

The variation in the $\mathrm{G}+\mathrm{C}$ contents of the genomes of the five bacteria in the cluster is remarkable; T. equigenitalis and $S$. volutans have $\mathrm{G}+\mathrm{C}$ contents of about $37 \mathrm{~mol} \%(7,18), C$. fluviatile has a G+C content of about $51 \mathrm{~mol} \%$ (15), and $A$. xylosoxidans and $B$. bronchiseptica have $\mathrm{G}+\mathrm{C}$ contents of about $69 \mathrm{~mol} \%(6,11)$. Although $\mathrm{G}+\mathrm{C}$ content is not a phylogenetic marker per se, such extreme variation is usually not found within a bacterial subdivision. Clearly, some additional parameters are needed to identify further subdivisions within the $\beta$ subclass of Proteobacteria.

The 16S rRNA gene sequences of Taylorella strains belonging to field inversion gel electrophoresis groups $\mathrm{A}$ and $\mathrm{C}$ are identical. This implies that the 16S rRNA gene sequences are not useful for epidemiological studies. On the other hand, the 16S rRNA gene may be useful as a target for a diagnostic polymerase chain reaction.

Nucleotide sequence accession numbers. The nucleotide sequence accession numbers for the $16 \mathrm{~S}$ rDNAs of $T$. equigenitalis, B. bronchiseptica S-1, A. xylosoxidans ATCC $15173^{\mathrm{T}}$, C. fluviatile ATCC 33051, L. pneumophila ATCC $33152^{\mathrm{T}}, P$. aeruginosa ATCC $25330, E$. coli, and $S$. volutans ATCC $19554^{\mathrm{T}}$ are X68645, X57026, M22509, M22511, M59157, M34133, J01695, and M34131, respectively.

The use of services and facilities of the Dutch National NWO/ SURF Expertise Center CAOS/CAMM under grants SON 326-052 and STW-NCH-99.1751 is gratefully acknowledged.

\section{REFERENCES}

1. Bleumink-Pluym, N., E. A. ter Laak, and B. A. M. van der Zeijst. 1990. Epidemiologic study of Taylorella equigenitalis strains by field inversion gel electrophoresis of genomic restriction endonuclease fragments. J. Clin. Microbiol. 28:2012-2016.

2. Crowhurst, R. C. 1977. Genital infection in mares. Vet. Rec. 100:476.

3. Felsenstein, J. 1985. Confidence limits on phylogenies: an approach using the bootstrap. Evolution 39:783-791.

4. Fitch, W. M., and E. Margoliash. 1967. Construction of phylogenetic trees. Science 155:279-284.

5. Garcia, E., H. E. N. Bergmans, J. F. van den Bosch, I. Orskov, B. A. M. van der Zeijst, and W. Gaastra. 1988. Isolation of and characterization of dog uropathogenic Escherichia coli strains and their fimbriae. Antonie van Leeuwenhoek 54:149-163.

6. Kersters, K., and J. De Ley. 1984. Genus Alcaligenes Castellani and Chalmers 1919, p. 361-373. In N. R. Krieg and J. G. Holt (ed.), Bergey's manual of systematic bacteriology, vol. 1. The Williams \& Wilkins Co., Baltimore.

7. Krieg, N. R. 1984. Aerobic/microaerophilic, motile, helical/ vibrioid gram-negative bacteria, p. 71-93. In N. R. Krieg and J. G. Holt (ed.), Bergey's manual of systematic bacteriology, vol. 1. The Williams \& Wilkins Co., Baltimore.

8. Logan, N. A. 1989. Numerical taxonomy of violet-pigmented, gram-negative bacteria and description of Iodobacter fluviatile gen. nov., comb. nov. Int. J. Syst. Bacteriol. 39:450-456.

9. Moss, M. O., and C. Ryall. 1981. The genus Chromobacterium, p. 1355-1364. In M. P. Starr, H. Stolp, H. G. Trüper, A. Balows, and H. G. Schlegel (ed.), The prokaryotes: a handbook 
on habitats, isolation, and identification of bacteria. SpringerVerlag KG, Berlin.

10. Olsen, G. J., R. Overbeek, N. Larsen, T. L. Marsh, M. J. McCaughey, M. A. Maciukenas, W. M. Kuan, T. J. Macke, Y. Q. Xing, and C. R. Woese. 1992. The Ribosomal Database Project. Nucleic Acids Res. 20:2199-2200.

11. Pittman, M. 1984. Genus Chromobacterium Bergonzini 1881, p. 580-582. In N. R. Krieg and J. G. Holt (ed.), Bergey's manual of systematic bacteriology, vol. 1. The Williams \& Wilkins Co. Baltimore.

12. Rossau, R., K. Kersters, E. Falsen, E. Jantzen, P. Segers, A. Union, L. Nehls, and J. De Ley. 1987. Oligella, a new genus including Oligella urethralis comb. nov. (formerly Moraxella urethralis) and Oligella ureolytica sp. nov. (formerly CDC group IVe): relationship to Taylorella equigenitalis and related taxa. Int. J. Syst. Bacteriol. 37:198-210.

13. Saitou, N., and M. Nei. 1987. A neighbour-joining method: a new method for constructing phylogenetic trees. Mol. Biol. Evol. 44:406-425.

14. Sanger, F., S. Nicklen, and A. R. Coulsen. 1977. DNA sequencing with chain-terminating inhibitors. Proc. Natl. Acad. Sci. USA 74:5463-5467.

15. Sneath, P. H. A. 1984. Genus Bordetella Moreno-Lopez 1952, p. 388-393. In N. R. Krieg and J. G. Holt (ed.), Bergey's manual of systematic bacteriology, vol. 1. The Williams \& Wilkins Co., Baltimore.

16. Stackebrandt, E., R. G. E. Murray, and H. G. Trüper. 1988. Proteobacteria classis nov., a name for the phylogenetic taxon that includes the "purple bacteria and their relatives." Int. J. Syst. Bacteriol. 38:321-325.

17. Sugimoto, C., Y. Isayama, R. Sakazaki, and S. Kuramochi. 1983 Transfer of Haemophilus equigenitalis Taylor et al. 1978 to the genus Taylorella gen. nov. as Taylorella equigenitalis comb. nov. Curr. Microbiol. 9:155-162.

18. Taylor, C. E. D., R. O. Rosenthal, D. F. J. Brown, S. P. Lapage, L. R. Hill, and R. M. Legros. 1978. The causative organism of contagious equine metritis 1977: proposal for a new species to be known as Haemophilus equigenitalis. Equine Vet. J. 10:136144.

19. ter Laak, E. A. 1981 . Contagious equine metritis 1977 (CEM). A review. Tijdschr. Diergeneeskd. 106:9-24.

20. Weisburg, W. G., S. M. Barns, D. A. Pelletier, and D. J. Lane. 1991. 16S ribosomal DNA amplification for phylogenetic study. J. Bacteriol. 173:697-703.

21. Williams, J. F. 1989. PCR questions and answers. Amplifications 3:19.

22. Woese, C. R. 1987. Bacterial evolution. Microbiol. Rev. 51:221271. 